\title{
PENGEMBANGAN WEBSIG OBYEK WISATA DAN BUDAYA DI KABUPATEN MOJOKERTO
}

\author{
Muhammad Taufik, Ayuarisa Ika Wandini \\ Program Studi Teknik Geomatika FTSP-ITS, Kampus ITS Sukolilo, Surabaya, 60111 \\ Email : mtaufik@geodesy.its.ac.id, dhinie.802@gmail.com
}

\begin{abstract}
Abstrak
Kabupaten Mojokerto terletak di daerah dataran rendah di bagian Sungai Brantas hingga dataran tinggi di lereng Pegunungan Penanggungan dan Welirang. Secara historis Kabupaten Mojokerto dipercaya merupakan wilayah Kerajaan Majapahit dan Kerajaan Kahuripan. Peninggalan sejarah dari masa Kerajaan Majapahit banyak ditemukan hampir di seluruh wilayah di Mojokerto dan peninggalan masa Airlangga (Kerajaan Kahuripan) di seputar lereng gunung Penanggungan. Penggunaan SIG dalam inventarisasi pariwisata dan kebudayan diharapkan mampu memberi petunjuk dan kemudahan bagi para wisatawan untuk memperoleh informasi mengenai pariwisata dan kebudayaan di Kabupaten Mojokerto.
\end{abstract}

Pada penelitian ini dilakukan pembuatan sistem informasi geografis berbasis Web menggunakan peta Rupa Bumi Indonesia skala 1:25.000 serta data tabular dari Dinas Pariwisata maupun hasil penelitian dilapangan.Pengolahan data spasial menggunakan ArcView 3.2, dan untuk menampilkan peta di web menggunakan Mapserver.

Hasil yang diperoleh dalam pembuatan sistem informasi ini adalah suatu aplikasi interaktif berbasis web yang dapat menunjukkan 59 obyek wisata, 5 kesenian, 8 budaya/ritual,dan 3 satuan kawasan wisata yang ada di Kabupaten Mojokerto.

Kata Kunci : WebGIS, Obyek wisata dan budaya,Kabupaten Mojokerto

\section{PENDAHULUAN}

Kabupaten Mojokerto secara topografis terletak pada daerah dataran rendah di bagian sungai Brantas hingga dataran tinggi di lereng pegunungan Penanggungan dan Welirang. Secara historis Kabupaten Mojokerto dipercaya merupakan wilayah kerajaan Majapahit dan Kerajaan Kahuripan. Peninggalan sejarah dari masa Kerajaan Majapahit banyak ditemukan hampir di seluruh wilayah di Mojokerto dan peninggalan masa Airlangga (Kerajaan Kahuripan) di seputar lereng Gunung Penanggungan.

Kabupaten Mojokerto memiliki potensi wisata yang sangat besar, baik wisata alam, sejarah, maupun wisata artifisial. Selain itu, Kabupaten Mojokerto juga memiliki kebudayaan atau kesenian dan tradisi yang beragam. Pengembangan pariwisata dan kebudayaan di Kabupaten Mojokerto, diyakini akan mampu meningkatkan kesejahteraan masyarakat sekitar, mengenalkan keragaman wisata dan budaya, dan mampu melestarikan kebudayaan yang berkembang di lingkungan daerah tersebut.
Penggunaan SIG dalam inventarisasi pariwisata dan kebudayan adalah salah satu cara yang dapat digunakan untuk membantu membuat perencanaan dan pengembangan daerah wisata karena SIG memberi kemudahan dalam mengakses, menyimpan, melakukan editing dan updating data. Selain itu, dengan adanya Web SIG diharapkan dapat memberi petunjuk dan kemudahan bagi para wisatawan untuk memperoleh informasi mengenai pariwisata dan kebudayaan di Kabupaten Mojokerto.

\section{Rumusan Permasalahan}

Rumusan masalah dalampenelitian ini adalah bagaimana upaya untuk menginventarisasi dan menganalisa obyek-obyek wisata dan kebudayaan yang ada di Kabupaten Mojokerto dan bagaimana penerapan WebSIG untuk mendukung pengembangan pariwisata dan kebudayaan di Kabupaten Mojokerto.

\section{Batasan Masalah}

Batasan masalah dari penelitian ini adalah: 
1. Wilayah studi hanya mencakup Kabupaten Mojokerto.

2. Peta yang digunakan adalah Peta digital dengan skala 1: 25.000 terbitan BAKOSURTANAL (Badan Koordinasi Survei dan Pemetaan Nasional) tahun 1999 sejumlah 15 sheet.

3. Hasil penelitian berupa Web SIG Daerah Pariwisata Kabupaten Mojokerto.

\section{Tujuan}

Penelitian tugas akhir ini bertujuan untuk membuat Web SIG yang mendeskripsikan tentang objek-objek wisata di Kabupaten Mojokerto dan Kebudayaan di daerah wisata sebagai petunjuk informasi perjalanan bagi masyarakat, khusunya wisatawan

\section{Manfaat}

Manfaat yang ingin diperoleh dari penelitian ini adalah adanya suatu sistem informasi mengenai daerah Pariwisata agar mudah diakses oleh masyarakat luas sehingga dapat dijadikan sebagai sarana informasi alternatif memperkenalkan pariwisata dan kebudayaan yang ada di Kabupaten Mojokerto.

\section{METODOLOGI PENELITIAN}

\section{Lokasi Penelitian}

Lokasi penelitian mengambil wilayah Kabupaten Mojokerto

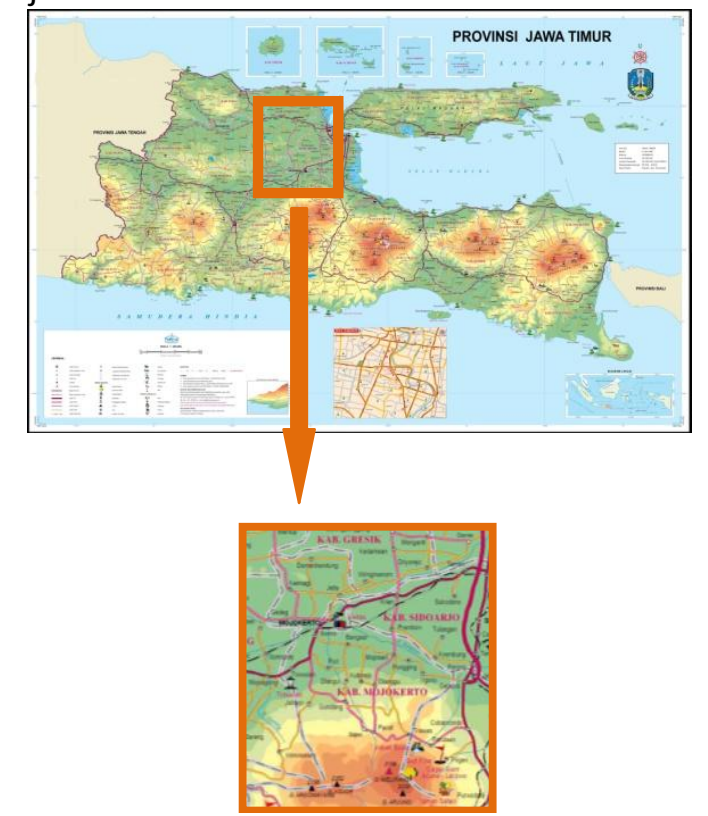

Gambar 1. Lokasi Penelitian (Bappeda Pacitan, 2008)

\section{DATA DAN PERALATAN \\ Data}

1. Peta Rupa Bumi Indonesia (RBI) tahun 1999 skala 1: 25.000 terbitan BAKOSURTANAL dengan indeks peta 1508-324, 1508-341, 1508-342, 1508-343, 1508-344, 1508-621, 1508-622, 1508-623, 1508-624, 1608-113, $1608-131$, 1608-132, 1608-133, 1608-134, 1608-411.

2. Data deskripsi obyek pariwisata dan kebudayaan dari Dinas Pariwisata Kabupaten Mojokerto, dan instansi terkait lainnya.

\section{Peralatan}

1. Perangkat Keras (Hardware)

a. Buah GPS Handheld Garmin untuk groundtruth.

b. Kamera digital untuk dokumentasi

2. Perangkat Lunak (Software)

a. Software ArcView GIS 3.2 untuk perancangan SIG.

b. Autodesk Land Desktop 2004 untuk digitasi peta

c. Notepad++ untuk pembuatan tampilan web.

d. Map Server untuk menampilkan peta di web.

\section{Diagram Alir}

Tahapan yang dilaksanakan dalam penelitian ini adalah :

\section{Tahap Awal Penelitian}

- Idientifikasi Masalah

Permasalahan yang berhasil diidientifikasi adalah adalah kurang maksimalnya peran web dalam keperluan publikasi dan promosi wisata di Kabupaten Mojokerto.

- Menetapkan Rumusan dan Batasan Masalah Menetapkan rumusan masalah bertujuan untuk menentukan masalah apa saja yang akan diselesaikan dalam penelitian ini. Menentukan batasan masalah bertujuan untuk membatasi permasalahan beserta metode yang digunakan agar tidak melebar dari rumusan masalah.

- Studi Literatur

Bertujuan mendapatkan referensi tentang pembuatan Sistem Informasi Geografis, perancangan Web SIG, Potensi pariwisata dan kebudayaan, dokumentasi dan literatur lain 
yang mendukung baik dari buku, jurnal, majalah, koran, internet dan lain-lain.

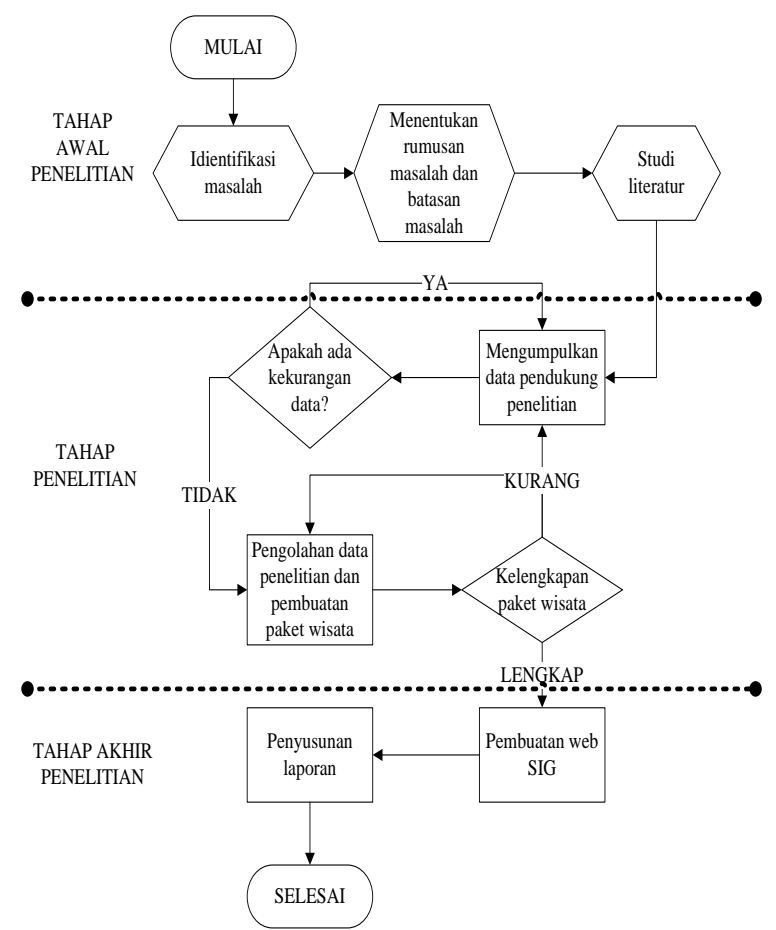

Gambar 2. Diagram Alir Penelitian

\section{Tahap Penelitian}

\section{Pengumpulan Data}

Pengumpulan Peta RBI Kabupaten Mojokerto skala 1:25000 sebanyak 15 sheet, data deskripsi obyek wisata dan budaya Kabupaten Mojokerto, dan data survey lapangan dan dokumentasi obyek peneilitian.

\section{- Pengolahan Data}

Tahapan pengolahan data penelitian ini dapat dilihat pada gambar 3 .

\section{Tahap Akhir Penelitian}

\section{- Pembuatan WebSIG}

Merancang file peta menggunakan notepad++ agar dapat ditampilkan dalam Mapserver. Untuk mendesain tampilan website menggunakan notepad++.

\section{- Penyusunan Laporan}

Penyusunan laporan merupakan tahap akhir dari penelitian tugas akhir.

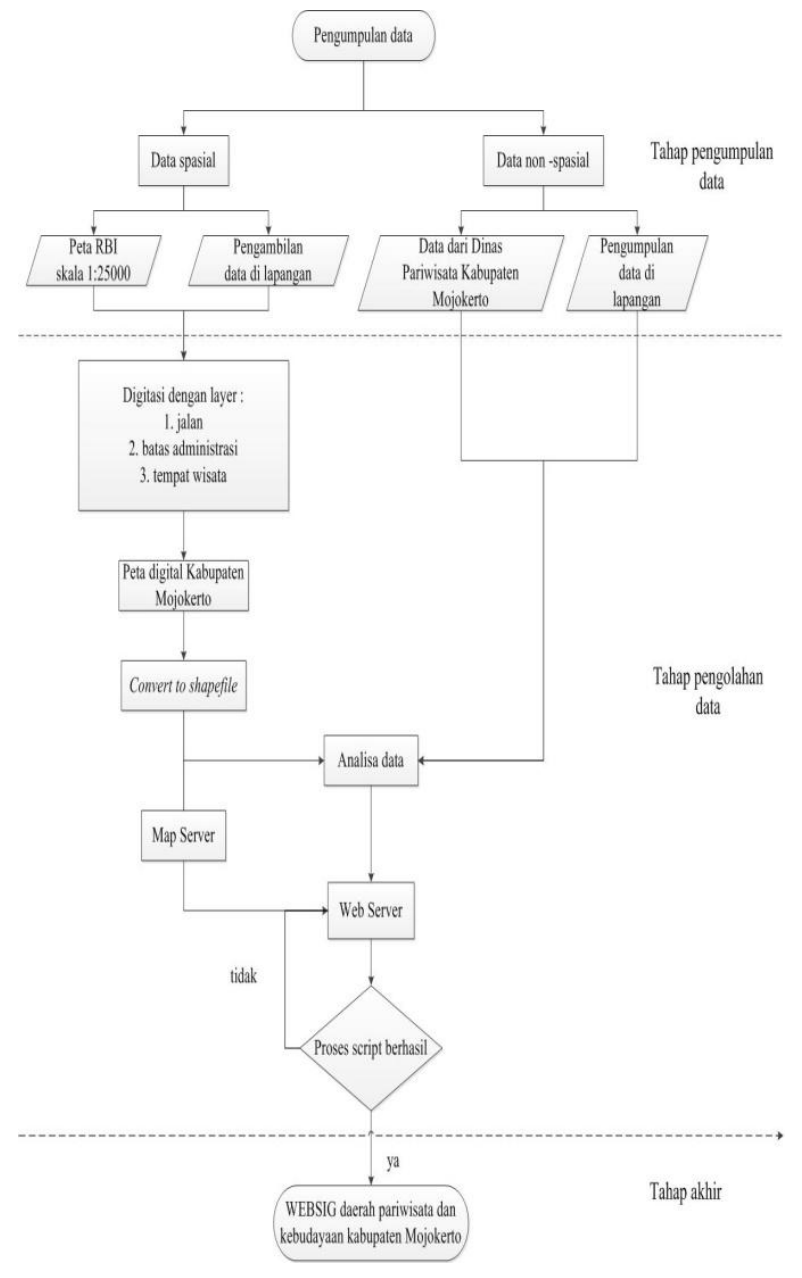

Gambar 3. Diagram Alir Pengolahan Data

\section{HASIL DAN PEMBAHASAN}

\section{Hasil Penelitian}

- Persebaran Obyek Wisata di Kabupaten Mojokerto

Dari data yang diperoleh, maka didapatkan hasil bahwa terdapat 59 obyek wisata yang tersebar di Kabupaten Mojokerto.

- Persebaran Seni dan Budaya di Kabupaten Mojokerto

Dari data yang diperoleh, baik dari dinas terkait maupun dari penelitian dilapangan, maka didapatkan hasil bahwa terdapat 5 kesenian dan 8 ritual atau kebudayaan yang berkembang di masyarakat Mojokerto.

- Satuan Kawasan Wisata di Kabupaten Mojokerto

Menurut Dinas Pariwista Kabupaten

Mojokerto terdapat 3 satuan kawasan 
wisata.Kawasan tersebut adalah sebagai berikut:
a. Satuan Kawasan Wisata Pacet
b. Satuan Kawasan Wisata Trawas
c. Satuan Kawasan Wisata Trowulan

Tabel 1. Sebaran Obyek Wisata

\begin{tabular}{cccc}
\hline No & Nama Kecamatan & $\begin{array}{c}\text { Jumlah Obyek } \\
\text { Wisata }\end{array}$ & $(\%)$ \\
\hline 1 & Bangsal & 2 & 3.4 \\
2 & Dawarblandong & 1 & 1.7 \\
3 & Dlanggu & - & - \\
4 & Gedeg & 1 & 1.7 \\
5 & Gondang & 1 & 1.7 \\
6 & Jatirejo & 5 & 8.5 \\
7 & Jetis & 2 & 3.4 \\
8 & Kemlagi & 1 & 1.7 \\
9 & Kutorejo & - & - \\
10 & Ngoro & 4 & 6.8 \\
11 & Mojoanyar & 1 & 1.7 \\
12 & Mojosari & - & - \\
13 & Pacet & 12 & 20.3 \\
14 & Pungging & - & - \\
15 & Puri & 3 & 5.1 \\
16 & Sooko & 1 & 1.7 \\
17 & Trawas & 6 & 10.2 \\
18 & Trowulan & 19 & 32.2 \\
& Jumlah & 59 & 100 \\
\hline
\end{tabular}

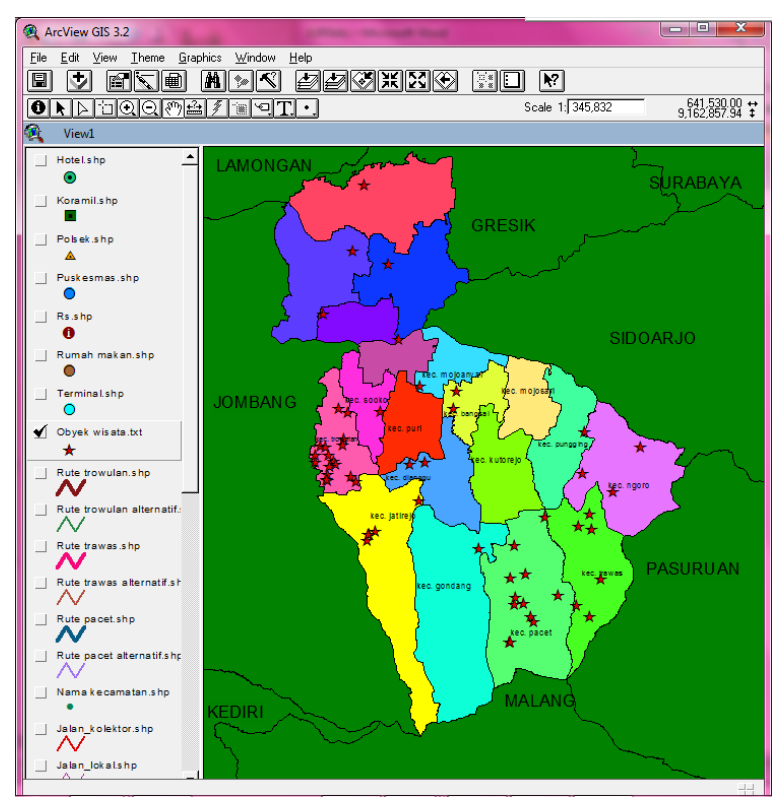

Gambar 4. Tampilan Peta Sebaran Obyek Wisata di ArcView 3.3
Tabel 2. Data kesenian di kabupaten Mojokerto

\begin{tabular}{ccc}
\hline No & Seni Budaya & Asal Daerah \\
\hline 1 & Bantengan & Pacet \\
2 & Kesenian Ludruk & Kemlagi dan Jetis \\
3 & Kesenian Ujung & Mojokerto \\
4 & Upacara Pengantin & Mojokerto \\
& Mojoputri & Trowulan \\
\hline
\end{tabular}

Tabel 3. Data Ritual dan Budaya yang ada di Kabupaten Mojokerto

\begin{tabular}{ccc}
\hline No & Kecamatan & Nama Budaya/ Ritual \\
\hline 1 & & Haul Syech Jumadil \\
Kubro \\
2 & Trowulan & Grebeg Suro \\
3 & & Ruwat Deso Jatipasar \\
4 & & Ruwat Deso Bejijong \\
5 & & Mocopat \\
6 & Trawas & Ritual Suroan \\
7 & Gedeg & Upacara 17 Agustus \\
8 & & Tayuban \\
\hline
\end{tabular}

\section{Pembagian Obyek Wisata}

\section{- Pembagian Obyek Wisata Berdasarkan Kategori Jenis Wisata}

Pembagian obyek wisata berdasarkan jenis wisata didasarkan pada karakter dan/atau aktifitas wisata dari obyek wisata tersebut. Pembagian ini didasarkan pada kategori utama dari jenis wisata sebuah obyek, karena tidak menutup kemungkinan bahwa sebuah obyek wisata memiliki lebih dari satu kategori.

\section{Tabel 4. Jumlah Obyek Wisata Berdasarkan Jenis} Wisata

\begin{tabular}{cccc}
\hline No & $\begin{array}{c}\text { Kategori Jenis } \\
\text { Wisata }\end{array}$ & $\begin{array}{c}\text { Jumlah Obyek } \\
\text { Wisata }\end{array}$ & (\%) \\
\hline 1 & Wisata Alam & 10 & 16.9 \\
2 & Wisata Artifisial & 13 & 22.0 \\
3 & Wisata Sejarah & 24 & 40.7 \\
4 & Wisata Ziarah & 12 & 20.3 \\
& Jumlah & $\mathbf{5 9}$ & $\mathbf{1 0 0}$ \\
\hline
\end{tabular}

\section{Pembagian Obyek Wisata Berdasarkan Tujuan Wisata}

Pembagian obyek wisata berdasarkan tujuan wisata didasarkan pada fasilitas yang ada di obyek wisata, dan mayoritas tujuan wisatawan yang mengunjungi obyek wisata. Setiap obyek wisata bisa menjadi lebih dari satu tujuan wisata. 
Tabel 5. Daftar Tujuan Wisata

\begin{tabular}{|c|c|c|}
\hline No & Tujuan Wisata & Jumlah Obyek Wisata \\
\hline 1 & Berkemah & 3 \\
\hline 2 & $\begin{array}{l}\text { Pendakian dan } \\
\text { petualangan }\end{array}$ & 5 \\
\hline 3 & Outbobd & 3 \\
\hline 4 & Pendidikan sejarah & 31 \\
\hline 5 & $\begin{array}{c}\text { Pendidikan lainnya } \\
\text { Berenang, }\end{array}$ & 3 \\
\hline 6 & $\begin{array}{l}\text { berendam, atau } \\
\text { bermain air }\end{array}$ & 11 \\
\hline 7 & Memancing & 2 \\
\hline 8 & Ziarah & 12 \\
\hline 9 & $\begin{array}{c}\text { Belanja dan Oleh- } \\
\text { oleh }\end{array}$ & 2 \\
\hline
\end{tabular}

\section{Pembagian Obyek Wisata Berdasarkan Rute Menuju Kawasan Wisata}

Pembagian obyek wisata berdasarkan rute menuju kawasan wisata didasarkan pada persebaran obyek wisata yang ada pada rute yang menuju kawasan wisata, baik rute utama maupun rute alternatif.

\section{Satuan Kawasan Wisata Pacet}

Untuk menuju kawasan wisata Pacet, dapat ditempuh melalui 5 rute utama dan 3 rute alternatif.

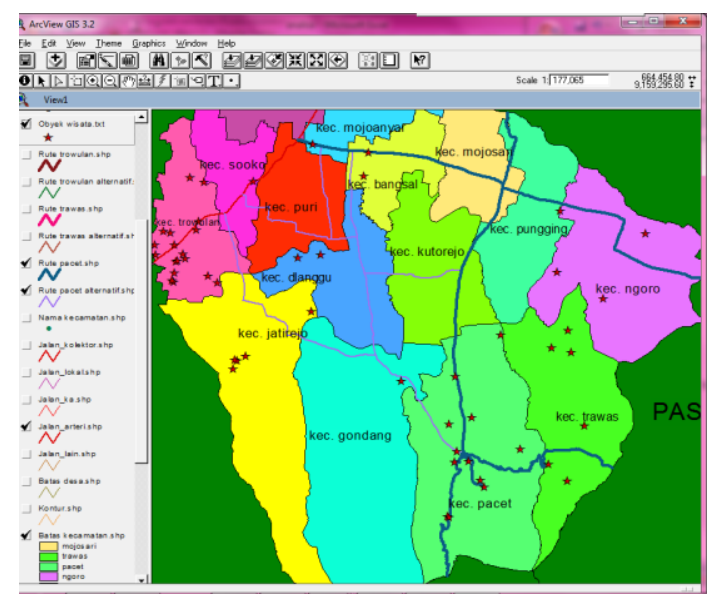

Gambar 5 Tampilan Peta Rute Menuju Kawasan Pacet

- Rute Utama

- Rute Mojokerto $\rightarrow$ Mojosari $\rightarrow$ Pacet ( 3 obyek wisata)

- Rute Krian $\rightarrow$ Mojosari $\rightarrow$ Pacet

- Rute Cangar $\rightarrow$ Pacet

- Rute Gempol $\rightarrow$ Ngoro $\rightarrow$ Pacet (4 obyek wisata)

- Rute Pandaan $\rightarrow$ Trawas $\rightarrow$ Pacet $(2$ obyek wisata)
- Rute Alternatif

- Rute Trowulan $\rightarrow$ Pacet via Kutorejo dan Gondang (1 obyek wisata)

- Rute Bangsal $\rightarrow$ Pacet via Dlanggu (1 obyek wisata)

- Rute Puri $\rightarrow$ Pacet via Dlanggu (2 obyek wisata)

\section{Satuan Kawasan Wisata Trawas}

Untuk menuju kawasan wisata Trawas, dapat ditempuh dengan 6 rute utama dan 4 rute alternatif.

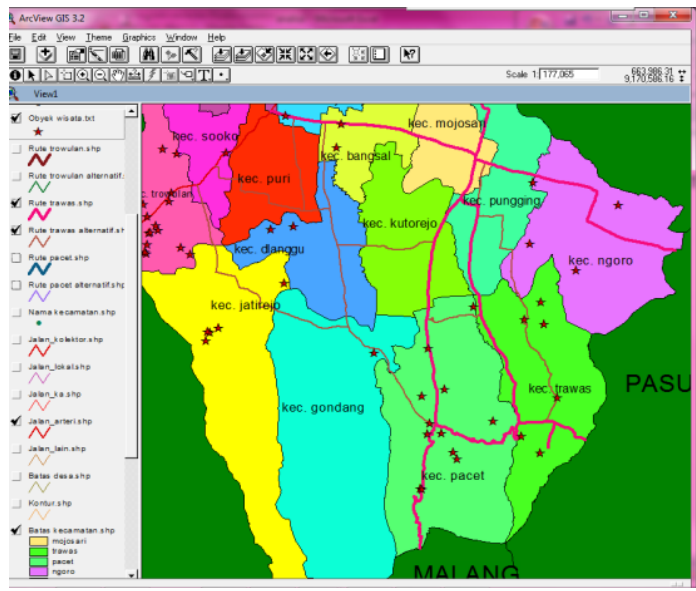

Gambar 6. Tampilan Peta Menuju Kawasan Trawas

- Rute utama

- Rute Mojokerto $\rightarrow$ Mojosari $\rightarrow$ Trawas (4 obyek wisata)

- Rute Mojokerto $\rightarrow$ Mojosari $\rightarrow$ Pacet $\rightarrow$ Trawas (6 obyek wisata)

- Rute Krian $\rightarrow$ Mojosari $\rightarrow$ Trawas

- Rute Cangar $\rightarrow$ Pacet $\rightarrow$ Trawas (4 obyek wisata)

- Rute Gempol $\rightarrow$ Ngoro $\rightarrow$ Pacet $\rightarrow$ Trawas (4 obyek wisata)

- Rute Pandaan $\rightarrow$ Trawas

- Rute Alternatif

- Rute Trowulan $\rightarrow$ Trawas via Kutorejo, Gondang dan Pacet (4 obyek wisata)

- Rute Bangsal $\rightarrow$ Trawas via Dlanggu dan Pacet (4 obyek wisata)

- Rute Puri $\rightarrow$ Trawas via Dlanggu dan Pacet ( 6 obyek wisata)

- Rute Pungging $\rightarrow$ Trawas via Ngoro 
3.Satuan Kawasan Wisata Trowulan Untuk menuju kawasan wisata Trowulan, hanya terdapat 1 rute utama dan 1 rute alternatif.

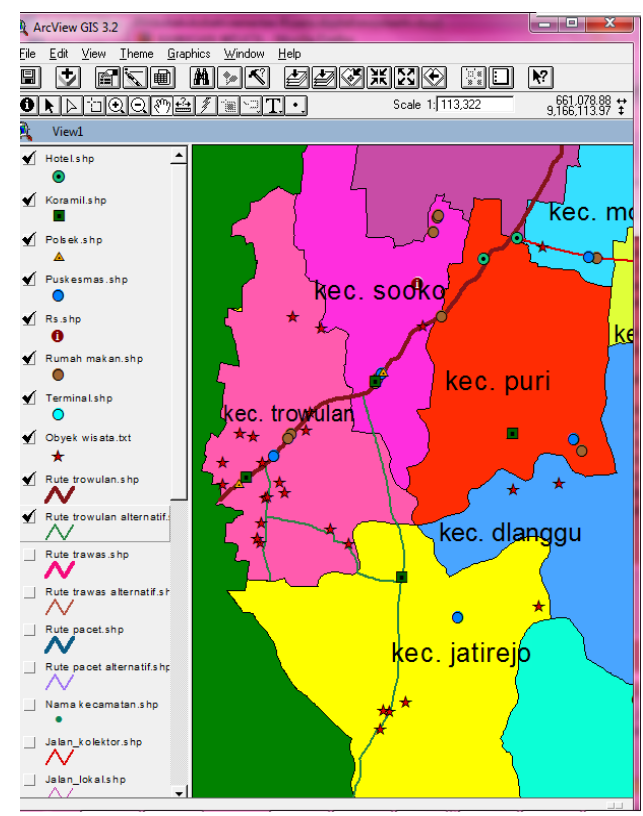

Gambar 7. Tampilan Peta Rute Menuju Kawasan Trowulan

- Rute utama

- Bypass Mojokerto (1 obyek wisata)

- Rute alternatif

- Jombang $\rightarrow$ Jatirejo $\rightarrow$ Trowulan (5 obyek wisata)

\section{Analisa}

Tujuan analisa data ini adalah untuk mengetahui apakah suatu obyek wisata mampu menarik minat wisatawan untuk berkunjung ke obyek wisata. Parameter yang digunakan adalah kesesuaian dengan tujuan kawasan wisata, bagaimana akses menuju obyek wisata, fasilitas yang disediakan untuk menunjang obyek wisata, obyek wisata lain yang ada di sekitar obyek wisata utama, pengelola obyek wisata, dan mitos atau ritual yang ada di obyek wisata tersebut. Indikator analisa adalah sebagai berikut:
Tabel 4.6 Variabel dan indikator dari parameter

\begin{tabular}{|c|c|c|}
\hline Variabel & Definisi variabel & Indikator \\
\hline $\begin{array}{l}\text { kawasan } \\
\text { wisata }\end{array}$ & $\begin{array}{l}\text { kesesuaian dengan tujuan } \\
\text { kawasan wisata yang ada di } \\
\text { daerah tersebut }\end{array}$ & $\begin{array}{c}\text { obyek wisata berada } \\
\text { dikawasan wisata } \\
\text { atau tidak } \\
\text { obyek wisata sesuai } \\
\text { dengan kawasan } \\
\text { wisata atau tidak }\end{array}$ \\
\hline $\begin{array}{l}\text { akses } \\
\text { menuju } \\
\text { obyek } \\
\text { wisata }\end{array}$ & $\begin{array}{c}\text { bagaimana akses menuju } \\
\text { obyek wisata }\end{array}$ & $\begin{array}{c}\text { bentuk jalan yang } \\
\text { dilalui, tidak rata } \\
\text { dan/atau berkelok- } \\
\text { kelok } \\
\text { jalan } \\
\text { besar/tidak(minimal } \\
\text { bisa dilewati } 2 \text { mobil } \\
\text { tanpa harus turun ke } \\
\text { tepi jalan) } \\
\text { jarak dari jalur utama } \\
\text { (jalur utama yang } \\
\text { dimaksud adalah rute } \\
\text { utama maupun rute } \\
\text { alternatif yang telah } \\
\text { ditentukan } \\
\text { sebelumnya) }\end{array}$ \\
\hline $\begin{array}{l}\text { fasilitas } \\
\text { yang } \\
\text { tersedia }\end{array}$ & $\begin{array}{l}\text { fasilitas yang disediakan } \\
\text { untuk menunjang obyek } \\
\text { wisata } \\
\text { fasilitas yang dimaksud disini } \\
\text { bukanlah fasilits untuk } \\
\text { menunjang wisatawan }\end{array}$ & $\begin{array}{c}\text { adanya fasilitas lain } \\
\text { selain obyek utama } \\
\text { wisata } \\
\text { taman bunga } \\
\text { diasumsikan bukan } \\
\text { merupakan fasilitas } \\
\text { pendukung obyek } \\
\text { wisata }\end{array}$ \\
\hline $\begin{array}{l}\text { obyek } \\
\text { wisata lain }\end{array}$ & $\begin{array}{l}\text { obyek wisata lain yang ada } \\
\text { disekitar obyek wisata utama }\end{array}$ & $\begin{array}{l}\text { Ada atau tidaknya } \\
\text { obyek wisata lain } \\
\text { disekitar obyek } \\
\text { wisata utama. } \\
\text { pengelola dibagi }\end{array}$ \\
\hline pengelola & $\begin{array}{c}\text { pengelola obyek wisata } \\
\text { adalah pihak yang mengelola } \\
\text { obyek wisata. }\end{array}$ & $\begin{array}{c}\text { menjadi } 3 \text { yaitu } \\
\text { swasta, pemerintah } \\
\text { kabupaten dan dinas } \\
\text { lain. }\end{array}$ \\
\hline $\begin{array}{l}\text { mitos/ } \\
\text { ritual }\end{array}$ & $\begin{array}{l}\text { mitos/kepercayaan/budaya } \\
\text { atau ritual yang ada di obyek } \\
\text { wisata tersebut yang mampu } \\
\text { mendukung peningkatan } \\
\text { pengunjung }\end{array}$ & $\begin{array}{c}\text { ada atau tidaknya } \\
\text { mitos, } \\
\text { kepercayaan/budaya } \\
\text { atau ritual yang ada } \\
\text { di obyek wisata } \\
\text { tersebut }\end{array}$ \\
\hline
\end{tabular}

Setelah menentukan indikator dari setiap variabel, maka dilakukan skoring agar mengetahui nilai dari setiap indikator. Nilai tertinggi diberikan kepada indikator yang paling baik. 
Tabel 7. Skala ukur untuk analisa

\begin{tabular}{|c|c|}
\hline Indikator & Skoring \\
\hline \multicolumn{2}{|l|}{ Kesesuaian dengan Kawasan Wisata } \\
\hline $\begin{array}{l}\text { sesuai dengan tujuan kawasan wisata } \\
\text { tidaks sesuai/tidak berada dalam kawasan }\end{array}$ & 2 \\
\hline $\begin{array}{l}\text { tidaks sesuai/tidak berada dalam kawasan } \\
\text { wisata }\end{array}$ & 1 \\
\hline \multicolumn{2}{|l|}{ Bentuk Jalan } \\
\hline tidak berkelok-kelok dan rata & 4 \\
\hline berkelok-kelok tapi rata & 3 \\
\hline \multicolumn{2}{|l|}{ Bentuk Jalan } \\
\hline tidak berkelok-kelok tapi tidak rata & 2 \\
\hline tidak rata dan berkelok-kelok & 1 \\
\hline \multicolumn{2}{|l|}{ Besar Jalan } \\
\hline jalan besar & 3 \\
\hline jalan sedang & 2 \\
\hline jalan kecil & 1 \\
\hline \multicolumn{2}{|l|}{ Jarak Dari Jalur Utama } \\
\hline 0-1 km dari jalur utama & 3 \\
\hline 1-2 km dari jalur utama & 2 \\
\hline > 2 km dari jalur utama & 1 \\
\hline \multicolumn{2}{|l|}{ Fasilitas Yang Tersedia } \\
\hline$>\mathbf{3}$ fasilitas & 3 \\
\hline 1-3 fasilitas & 2 \\
\hline tidak ada fasilitas lain & 1 \\
\hline \multicolumn{2}{|l|}{ Obyek Wisata Lain } \\
\hline > 3 obyek wisata & 3 \\
\hline 2-3 obyek wisata & 2 \\
\hline 0-1 obyek wisata & 1 \\
\hline \multicolumn{2}{|l|}{ Pengelola } \\
\hline Swasta & 3 \\
\hline Bp3 dan dinas lain & 2 \\
\hline Pemerintah Kab dan Desa & 1 \\
\hline \multicolumn{2}{|l|}{ Mitos/Kepercayaan/Budaya/Ritual } \\
\hline ada & 2 \\
\hline tidak ada & 1 \\
\hline
\end{tabular}

dari hasil poengolahan data dan analisa, diperoleh hasil sebagai berikut:

Tabel 8 Hasil Analisa berdasarkan Jenis Wisata

\begin{tabular}{ccccc}
\hline $\begin{array}{c}\text { Jenis } \\
\text { Wisata }\end{array}$ & Menarik & $\begin{array}{c}\text { Kategori } \\
\text { Cukup } \\
\text { Menarik } \\
\end{array}$ & $\begin{array}{c}\text { Kurang } \\
\text { Menarik }\end{array}$ & Jumlah \\
\hline 19/d 23 & $\mathbf{1 3}$ s/d 18 & $\mathbf{8}$ s/d 12 & \\
\hline Alam & 2 & 7 & 2 & $\mathbf{1 1}$ \\
Ziarah & 0 & 8 & 4 & $\mathbf{1 2}$ \\
Artifisial & 4 & 9 & 1 & $\mathbf{1 4}$ \\
Sejarah & 0 & 16 & 6 & $\mathbf{2 2}$ \\
Jumlah & $\mathbf{6}$ & $\mathbf{4 0}$ & $\mathbf{1 3}$ & $\mathbf{5 9}$ \\
\hline
\end{tabular}

\section{- WebSIG}

Halaman web terdiri dari lima menu, diantaranya:

\section{a. Home}

Berisi informasi mengenai Kabupaten Mojokerto. Submenu yang ada dalam home antara lain geografis, administratif, kebudayaan, dan sejarah.

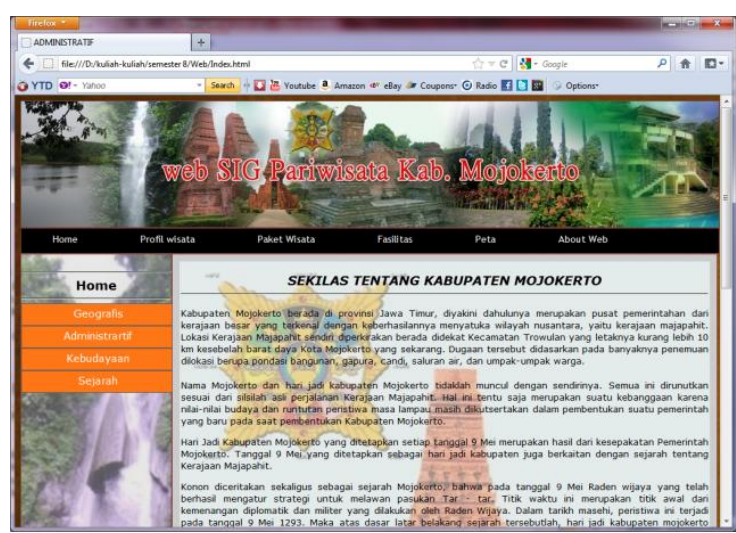

Gambar 8. Tampilan Menu Home pada WebSIG

\section{b. Profil Wisata}

Pada menu profil wisata, terdapat deskripsi mengenai obyek wisata, seni dan budaya, serta deskripsi mengenai satuan kawasan wisata di Kabupaten Mojokerto.

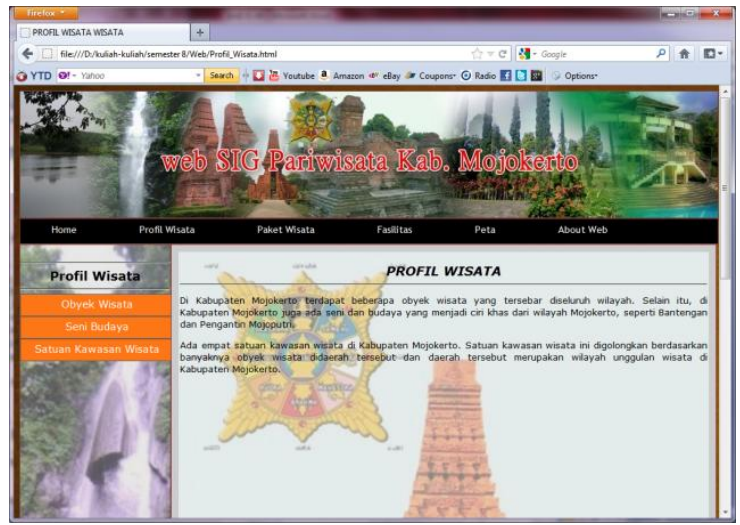

Gambar 9. Tampilan Menu Profil Wisata pada WebSIG

\section{c. Paket Wisata}

Pada menu Paket Wisata, ada beberapa pilihan paket, yaitu paket wisata berdasarkan jenis wisata, tujuan wisata, atau berdasarkan rute wisata yang dilalui. 


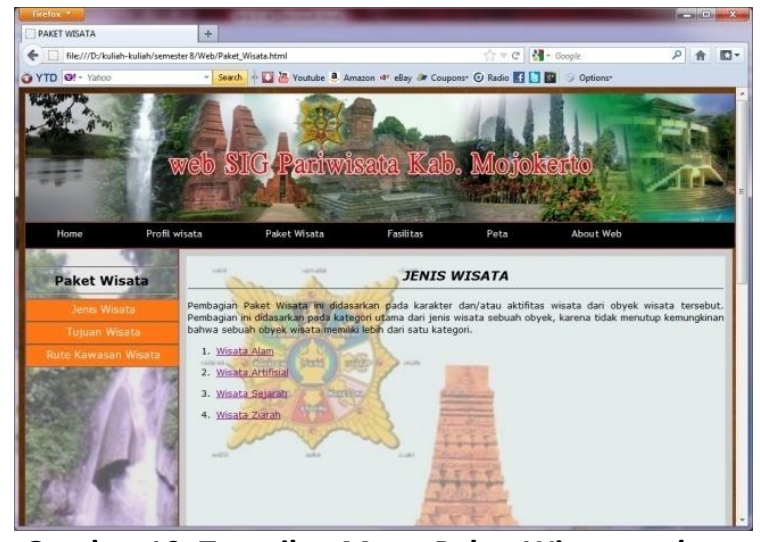

Gambar 10. Tampilan Menu Paket Wisata pada WebSIG

\section{d. Fasilitas}

Fasilitas yang ada pada menu Fasilitas adalah fasilitas yang mendukung obyek wisata, seperti hotel/penginapan, rumah makan, kantor polisi, kantor koramil, puskesmas, rumah sakit, dan kantor pos. terdapat juga peta fasum untuk memudahkan pengunjung agar mengetahui dimana letak fasilitas umum.

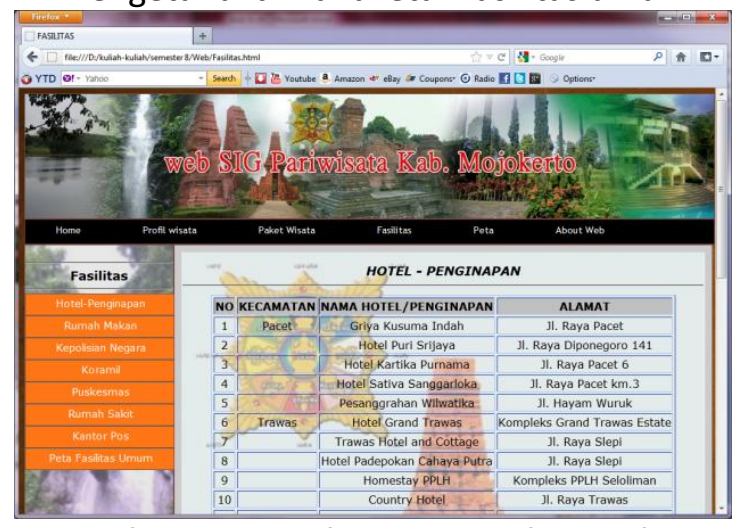

Gambar 11. Tampilan Menu Fasilitas pada WebSIG

\section{e. Peta}

Dalam tampilan menu Peta, ada dua submenu, yaitu peta wisata dan peta SIG. Peta wisata adalah peta dari Dinas Pariwisata, sedangkan peta SIG adalah peta interaktif.

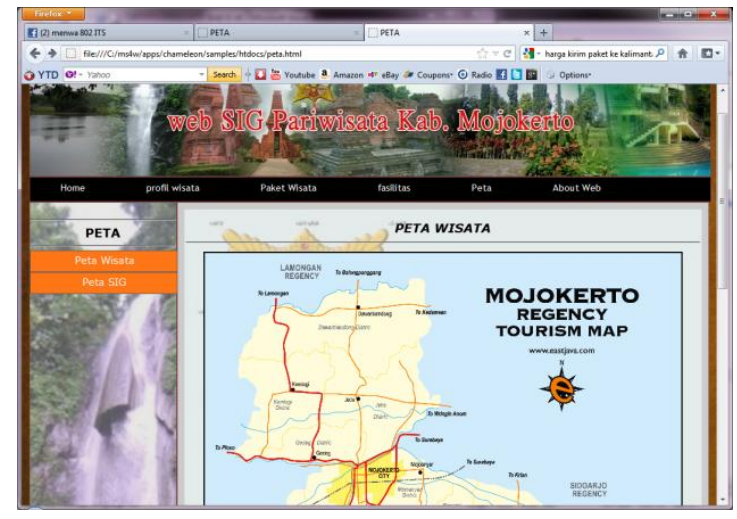

Gambar 12. Tampilan Menu Peta pada WebSIG

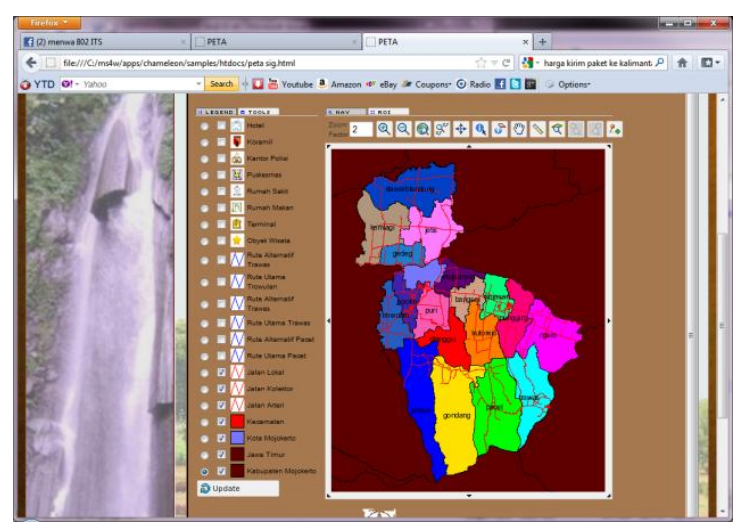

Gambar 13. Tampilan Menu Peta SIG

\section{f. About Web}

Dalam tampilan About Web, dijelaskan alasan dibuatnya web ini.

\section{KESIMPULAN dan SARAN}

\section{Kesimpulan}

Dari hasil penelitian dapat disimpulkan bahwa:

1. Di Kabupaten Mojokerto memiliki 59 obyek wisata, 5 kesenian, dan 8 budaya/ritual yang berkembang di masyarakat Mojokerto.

2. Informasi yang ditampilkan merupakan data yang menunjukan persebaran obyek wisata dan budaya yang ada di Kabupaten Mojokerto.

3. Paket wisata yang ada pada WebSIG ini didasarkan pada jenis wisata, tujuan wisata, dan rute menuju loksai wisata.

4. Telah dibuat WebSIG untuk mendukung pengembangan pariwisata dan kebudayaan di Kabupaten Mojokerto.

5. WebSIG dapat diakses melalui http://10.136.12.225/chameleon/samples/peta sig.html secara intranet. 


\section{Saran}

1. Pemerintah Kabupaten Mojokerto diharapkan agar pengembangan obyek wisata lebih merata agar tidak terpusat di wilayah selatan dan wilayah tengah Kabupaten Mojokerto.

2. Pemerintah Kabupaten Mojokerto diharapkan agar meningkatkan kegiatan rutin untuk melestarikan kesenian dan kebudayaan yang ada di Kabupaten Mojokerto.

3. Adanya penelitian lanjutan untuk menganalisa pengaruh jumlah pengunjung terhadap perkembangan wisata dan budaya di Kabupaten Mojokerto.

\section{DAFTAR PUSTAKA}

Adhitya, B.T. 2011. Inventarisasi Wisata kesenian dan Budaya Kota Cirebon dengan Sistem Informasi Geografis. Teknik Geomatika-ITS. Surabaya.

Anonim,

http://regionalinvestment.bkpm.go.id/newsipid/id /area.php?ia=3516, dikunjungi pada tanggal 17 Januari 2012 pukul 12.00 WIB.

Anonim,

http://regionalinvestment.bkpm.go.id/newsipid/id /area.php?ia=3516, dikunjungi pada tanggal 17 Januari 2012 pukul 12.00 WIB.

Anonim. 2007. Pendataan, Evaluasi, dan Monitoring Pariwisata. Dinas Pariwisata dan Kebudayaan, Pemerintah Kabupaten Mojokerto.

Aronoff, S. 1989. Geographic Information Systems: A Management Perspective. Ottawa,Canada:WDL Publications.

Budiyanto, E. 2005. Sistem Informasi Geografis Menggunakan ArcView Gis, Cetakan Kedua. Andi : Yogyakarta.

Damanik, J. 2006. Perencanaan Ekowisata. Andi : Yogyakarta

Data Geografis. http://www.mojokertokab.go.id/mjk/src/index.ph $p ? h f=1120 \&$ submenu=geografis, dikunjungi pada tanggal 30 Januari 2012 pukul 12.22 WIB

Grafitasari, A Dan Hariyanto, T. 2012. Perancangan Sistem Informasi Geografis berrbasis Web untuk Inventarisasi Data Air Tanah dan Pertambangan Umum di Jawa Timur. Geoid, Volume 7 No. 2 : 153-162.
Guruvalah. 2008. Pengertian Kebudayaan Dan Seni. Http://www.guruvalah.20m.com. SMK Negeri 1 Samarinda, Dinas Pendidikan Kota Samarinda.

Jenis

http://www.scribd.com/doc/57911624/Jenis-

Pariwisata,

Pariwisata, dikunjungi pada tanggal 19 Januari 2012 pukul 11.48 WIB.

Mengenal map server. http://www.inigis.com/mengenal-mapserver/103, dikunjungi pada tanggal 17 Januari 2012 pukul 16.21 WIB.

Nobe, A.D.S. 2011. Pengembangan SIG untuk inventarisasi dan pengembangan Daerah Wisata di Kabupaten Manggarai Barat. Teknik GeomatikaITS. Surabaya.

Pengertian dasar kepariwisataan. http://caretourism.wordpress.com/2010/08/12/p engertian-dasar-kepariwisataan/, dikunjungi pada tanggal 16 Januari 2012 pukul 10.57 WIB.

Pengertian pariwisata, http://www.anneahira.com/pengertianpariwisata.htm, dikunjungi pada tanggal 16 Januari 2012 pukul 10.56 WIB.

Peta,_http://bpnjatim.wordpress.com/petajawatimur/. Dikunjungi pada tanggal 6 Februari 2012, jam 07.36 WIB.

Prahasta, E. 2005. Sistem Informasi Geografis. Edisi Revisi, Cetakan Kedua. C.V.Informatika : Bandung.

Prahasta, E. 2007. Membangun Aplikasi Web-Baseg GIS dengan Mapserver. CV. Informatika : Bandung.

Prahasta, E. 2007. Tutorial Arc View. Edisi, Cetakan Keempat. C.V.Informatika : Bandung.

Rahmat. Sejarah Kerajaan majapahit. http://blog.re.or.id/sejarah-kejayaan-kerajaanmajapahit.htm, dikunjungi pada tanggal $27 \mathrm{Mei}$ 2012 pukul 17.13 WIB.

Satoto, G dan Taufik, M. 2012. Pembuatan Sistem Informasi Pariwisata Berbasis Web dan Analisa Potensi Pariwisata di Kabupaten Pacitan. Geoid, Volume 7 No. 2 : 170-179.

Trisnawati, A.R. 2011. Pembuatan Sistem Informasi Bangunan Cagar Budaya Berbasis WebGIS. Teknik Geomatika-ITS. Surabaya.

Wardoyo, R., dan Andeka, R.T. 2008. Perancangan Dan Implementasi Webgis Pariwisata Kabupaten Sumba Timur. 